\title{
The Antimicrobial Peptide hLF1-11 Drives Monocyte-Dendritic Cell Differentiation toward Dendritic Cells That Promote Antifungal Responses and Enhance Th17 Polarization
}

\author{
Anne M. van der Does ${ }^{a}$ Simone A. Joosten ${ }^{a}$ Evy Vroomans $^{a}$ \\ Sylvia J.P. Bogaards ${ }^{b}$ Krista E. van Meijgaarden ${ }^{a}$ Tom H.M. Ottenhoff ${ }^{a}$ \\ Jaap T. van Dissel ${ }^{\mathrm{a}}$ Peter H. Nibbering ${ }^{\mathrm{a}}$ \\ a Department of Infectious Diseases, Leiden University Medical Center, Leiden, and bepartment of Physiology, \\ VU University Medical Center, Amsterdam, The Netherlands
}

\section{Key Words \\ Dendritic cell $\cdot$ Monocytes $\cdot$ Antimicrobial peptide . \\ T lymphocyte $\cdot$ Polarization $\cdot$ Candida albicans}

\begin{abstract}
The hLF1-11 peptide comprising the first $11 \mathrm{~N}$-terminal residues of human lactoferrin exerts antimicrobial activity in vivo, enhances the inflammatory response of monocytes and directs monocyte-macrophage differentiation toward cells with enhanced antimicrobial properties. In this study, we investigated the effects of hLF1-11 on human monocytedendritic cell (DC) differentiation and subsequent $T$ cell activation. Results revealed that - compared to control (peptideincubated) DCs - hLF1-11-differentiated DCs displayed enhanced expression of HLA class II antigens and dectin-1, and increased phagocytosis of Candida albicans. In addition, hLF1-11-differentiated DCs produced enhanced amounts of reactive oxygen species, IL- 6 and IL-10, but not IL-12p40 and TNF- $\alpha$, upon stimulation with C. albicans. Moreover, 6-daycultured hLF1-11-differentiated DCs and control (peptideincubated) DCs that had been stimulated with a Th17-inducing mix of antigens (including C. albicans) for $24 \mathrm{~h}$ were cocultured with autologous CD4+ T cells for $72 \mathrm{~h}$ and then the
\end{abstract}

levels of IL-10, IL-17 and IFN- $\gamma$ production and the percentage of cytokine-producing $T$ cells were assessed. The results revealed that the hLF1-11-differentiated DCs induced an enhanced IL-17, but reduced IFN- $\gamma$, production by T cells as compared to control (peptide-incubated) DCs. Collectively, the hLF1-11 peptide drives monocyte-DC differentiation toward DCs that promote antifungal responses and enhance Th17 polarization.

Copyright $\odot 2012$ S. Karger AG, Basel

\section{Introduction}

In tissues, dendritic cells (DCs) have the capacity to recognize and process pathogens and following their migration to the lymph nodes, present pathogen-derived antigens to $\mathrm{T}$ cells, thereby shaping an adaptive immune response. DCs can differentiate from a precursor cell depending on factors present in the local microenvironment. For example, when monocytes upon entering tissues encounter inflammatory mediators like cytokines, growth factors, chemokines, complement components and antimicrobial peptides (AMPs), they differentiate into immature DCs (iDC). These cells are known for

\section{KARGER}

Fax +41613061234

E-Mail karger@karger.ch

www.karger.com
(C) 2012 S. Karger AG, Basel

$1662-811 X / 12 / 0043-0284 \$ 38.00 / 0$

Accessible online at:

www.karger.com/jin
Dr. Peter H. Nibbering

Department of Infectious Diseases

Leiden University Medical Center (LUMC), C5-P

Albinusdreef 2, NL-2333 ZA Leiden (The Netherlands)

Tel. +31 71526 2204, E-Mail p.h.nibbering@lumc.nl 
abundant expression of pathogen recognition receptors and HLA class II molecules, efficient antigen uptake and processing capacities. Upon tissue injury triggered by microbial agents or other danger signals, iDCs mature into antigen-presenting cells that produce inflammatory mediators, migrate toward lymphoid organs and instruct $\mathrm{T}$ lymphocytes to proliferate and differentiate into specific $\mathrm{T}$ cell subsets. This polarization of $\mathrm{T}$ cells depends greatly on the DCs and the inflammatory mediators, e.g. antimicrobial peptides, present in their environment.

AMPs are often cationic, relatively short and active against a variety of microorganisms including multidrug-resistant pathogens [1]. An increasing number of studies show the diversity in the mechanisms of action of these peptides, i.e. direct killing of pathogens [2,3], modulation of pathogen development $[4,5]$ and modulation of immune cells [6-8] and were therefore also named as 'host defense peptides' (HDPs) $[9,10]$. For possible therapeutic application of HDPs, it will be important to understand the interactions of these peptides with the host's immune cells. For example, cathelicidin-based peptides IDR-1 [11] and IDR1002 [12] have been developed on the basis of their ability to enhance chemokine production by innate immune cells. The cathelicidin LL-37 is able to direct both monocyte-macrophage differentiation [13] as well as differentiation toward DCs that promote a Th1 response in vitro [14] through interaction with an intracellular target [15]. LL-37 is also able to modulate the adaptive immune response by directly affecting the maturation of DCs [16].

We recently reported that the antimicrobial peptide comprising the first $11 \mathrm{~N}$-terminal residues of human lactoferrin, further referred to as hLF1-11, enhances the inflammatory response of monocytes and modulates monocyte-macrophage differentiation, an additional mechanism of action to its already established antimicrobial effects $[3,5,17]$. hLF1-11 enhances inflammatory mediator production by murine and human monocytes [18] and promotes GM-CSF-driven monocyte-macrophage differentiation toward a macrophage subset that shows enhanced responsiveness to microbial stimuli and demonstrates increased clearance of pathogens [6]. Since monocytes can also differentiate toward (immature) DCs, we have investigated the effects of hLF1-11 on monocyte-DC differentiation. We found that when hLF1-11 was present during GM-CSF/IL-4-driven differentiation of monocytes toward DCs, the resulting iDCs displayed enhanced antifungal responses against C. albicans and - upon maturation - enhanced IL-17 production while reducing IFN- $\gamma$ production by $\mathrm{T}$ cells.

\section{Materials and Methods}

Peptides

The human lactoferrin-derived peptide hLF1-11 (GRRRRSVQWCA; $1.374 \mathrm{kDa}$ ) was purchased from Peptisyntha (Torrance, Calif., USA) and the control peptide (GAARRAVQWAA; 1.115 $\mathrm{kDa}$ ) from Isogen (De Meern, The Netherlands). The control peptide shows no activity against pathogens in vitro and in vivo [5]. The purity of both peptides was $>97 \%$ as determined by reversephase high-performance liquid chromatography. Stocks of the peptides were made in phosphate-buffered saline (PBS, Department of Pharmacy LUMC, Leiden, The Netherlands) and stored at $-20^{\circ} \mathrm{C}$. Endotoxin concentrations were below detection level.

\section{Cell Culture}

Peripheral blood mononuclear cells were isolated from buffy coats of healthy donors using Ficoll-amidotrizoate density gradient centrifugation. Monocytes were further purified by CD14positive selection using anti-CD14-conjugated magnetic microbeads (Miltenyi Biotec, Bergisch Gladbach, Germany) according to manufacturer's protocol. Next, monocytes ( $>95 \%$ pure, viability $>96 \%$ as determined by propidium iodide staining) were incubated for 7 days in culture medium (RPMI-1640, Gibco Invitrogen, Breda, The Netherlands) containing 10\% heat-inactivated fetal bovine serum (Greiner Bio-One BV, Alphen a/d Rijn, The Netherlands), $2 \mathrm{~mm}$ penicillin, $2 \mathrm{mM}$ streptomycin (both PAA $\mathrm{GmbH}$, Pasching, Germany) and $2 \mathrm{~mm}$ L-glutamine (Gibco Invitrogen) supplemented with $10 \mathrm{ng} / \mathrm{ml}$ recombinant human granulocyte macrophage-colony stimulating factor (rhGM-CSF) and $10 \mathrm{ng} / \mathrm{ml}$ recombinant human IL-4 (both Biosource, Camarillo, Calif., USA). To study the effect of hLF1-11 on differentiation of monocytes into iDCs, at the start of the culture, monocytes were exposed to various concentrations of hLF1-11 (up to $100 \mu \mathrm{g} / \mathrm{ml}$ ), control peptide $(100 \mu \mathrm{g} / \mathrm{ml})$ or saline. On day 6 , the iDCs were matured with heat-killed $\left(30 \mathrm{~min}\right.$ at $\left.100^{\circ} \mathrm{C}\right)$ Candida albicans $\left(1 \times 10^{7} \mathrm{CFU} / \mathrm{ml}\right.$ strain Y01-19, Pfizer Inc., Groton, Conn., USA) for $20 \mathrm{~h}$. Thereafter, supernatants were harvested for assessment of cytokine (and chemokine) levels, or iDCs and mature DCs were harvested at day 7 and used for analysis of their endocytic and phagocytic activities and their ability to produce reactive oxygen species (ROS) and to polarize CD4+ T cell differentiation in coculture experiments.

Flow Cytometric Analysis of Cell Surface Molecule Expression by DCs

For measurements of the expression of a variety of cell surface molecules, the following monoclonal antibodies were used: phycoerythrin (PE)-conjugated antibodies directed against CD11b, CD40, CD54, CD80, CD83 and CD86 and fluorescein isothiocyanate (FITC)-labeled antibodies against HLA-DR, CD14, CD206 and CD209 were all obtained from BD Biosciences (Heidelberg, Germany). PE-conjugated antibody against dectin-1 was purchased from R\&D Systems and Alexa Fluor 647-conjugated antibody against CD197 from BD Biosciences. DCs were harvested and resuspended in ice-cold $0.2 \% \mathrm{PBS} / \mathrm{BSA}$, washed twice and then incubated with the selected antibodies for 30 min on ice in the dark. Cell surface molecule expression was assessed on a FACSCalibur and analyzed by BD CellQuest software (BD Biosciences). Results are expressed as median fluorescence intensity (MFI) corrected for background measurements. 
Flow-Cytometric Analysis of Dextran-FITC Uptake by DCs

The endocytic property of the various iDCs was examined by incubation of the cells with $1 \mathrm{mg} / \mathrm{ml}$ FITC-labeled dextran (Invitrogen) for $2 \mathrm{~h}$ at $37^{\circ} \mathrm{C}$ in culture medium. Background measurements were performed at $4^{\circ} \mathrm{C}$. After washing, dextran-FITC fluorescence was assessed using a FACSCalibur and analyzed by BD CellQuest software (BD Biosciences). The results are expressed as MFI corrected for background measurements.

Assays for the Phagocytosis of Staphylococcus aureus and C. albicans by Immature DCs

Phagocytosis of pHrodo-labeled $S$. aureus was performed as described for macrophages [6]. Briefly, a stock suspension of pHrodo-labeled S. aureus (Invitrogen) was prepared according to manufacturer's protocol. pHrodo is a dye that is non-fluorescent at neutral $\mathrm{pH}$ and bright red in acidic environments (e.g. phagolysosome). Equal volumes of iDCs $\left(1 \times 10^{6} / \mathrm{ml}\right)$ and 5 times prediluted pHrodo-labeled $S$. aureus stock were mixed and then incubated for several intervals of time at $37^{\circ} \mathrm{C}$, or as a control, at $4{ }^{\circ} \mathrm{C}$. Thereafter, pHrodo fluorescence of the iDCs was assessed on a FACSCalibur. Results are expressed as the percentage of pHrodopositive iDCs.

Phagocytosis of C. albicans by iDCs was assessed by FACS analysis as described for macrophages [6]. In short, C. albicans cultured overnight were washed twice in PBS and then labeled with $0.5 \mu \mathrm{M}$ carboxyfluorescein succinimidyl ester (CFSE, Invitrogen) for $30 \mathrm{~min}$ at $37^{\circ} \mathrm{C}$ in the dark, centrifuged and resuspended in RPMI-1640 supplemented with $20 \%$ human serum. iDCs were washed twice in $\mathrm{PBS} / 0.2 \%$ bovine serum albumin (BSA) and then labeled with PE-conjugated antibody against CD54 for $30 \mathrm{~min}$ (on ice in the dark). Next, these labeled iDCs were mixed with CFSE-labeled C. albicans in a 1:1 ratio and incubated for various intervals at $37^{\circ} \mathrm{C}$ under slow rotation in the dark. The percentage of iDCs associated with C. albicans was assessed by determining the percentage of double-positive iDCs (CD54+/ CFSE+) using a FACSCalibur and analyzed by BD CellQuest software. Control experiments were performed at $4^{\circ} \mathrm{C}$ to correct for binding of C. albicans to iDCs. Results are expressed as percentage iDCs that were positive for both CD54 and CFSE.

Flow Cytometric Analysis of ROS Production by DCs

Intracellular ROS production by iDCs was quantified using the fluorescent probe $2^{\prime}, 7^{\prime}$-dichlorofluorescein-diacetate (DCFHDA) (Invitrogen). In short, iDCs were loaded with $10 \mu \mathrm{M}$ DCFH$\mathrm{DA}$ for $20 \mathrm{~min}$ at $37^{\circ} \mathrm{C}$ in the dark. Thereafter, iDCs were incubated with $1 \times 10^{7}$ heat-killed C. albicans for various intervals of time. ROS production was measured on a FACSCalibur. The results are expressed as MFI with interquartile range.

\section{Determination of Cytokine Levels by ELISA}

Enzyme-linked immunosorbent assay (ELISA) cytosets were used to determine the concentrations of interleukin (IL)-6, IL-10, IL-12p40 and TNF- $\alpha$ (Invitrogen) according to manufacturer's instructions.

\section{T Cell Isolation and DC-T Cell Cocultures}

CD4+ T cells ( $>95 \%$ purity) were obtained from the CD14negative fraction after monocyte isolation (stored at $-80^{\circ} \mathrm{C}$ ) by CD4-positive selection using anti-CD4-conjugated magnetic microbeads (Miltenyi Biotec) according to the manufacturer's pro- tocol. They were resuspended in Iscove's Modified Dulbecco's Medium (Lonza, Verviers, Belgium) containing 10\% heat-inactivated fetal bovine serum(Gibco), antibiotics and $2 \mathrm{mM}$ L-glutamine and left overnight to recover. iDCs were reseeded in a 96well plate $\left(1 \times 10^{5} /\right.$ well $)$. Three hours thereafter, cells were stimulated with a Th17-favoring mix comprising of purified protein derivative of Mycobacterium tuberculosis (PPD, Statens Serum Institute, Copenhagen, Denmark; $5 \mu \mathrm{g} / \mathrm{ml}$ ) [19, 20], lipopolysaccharide (LPS, 100 ng/ml; Sigma-Aldrich, Zwijndrecht, The Netherlands), tetanus toxoid (TT; $1 \%$ of the stock, $80 \mathrm{IU} / \mathrm{ml})[21,22]$ and heat-killed C. albicans $\left(1 \times 10^{6} / \mathrm{ml}\right)[20,22]$. Twenty-four hours thereafter, DCs were cocultured with $1 \times 10^{6}$ autologous T cells for $72 \mathrm{~h}$ in the presence of TT ( $1 \%$ of the stock, $80 \mathrm{IU} / \mathrm{ml})$ and supernatants were collected and assessed for IL-17, IL-10, IFN- $\gamma$, IL-2 and IL-4 levels using a custom-made multiplex bead-array (Bio-Rad, Hercules, Calif., USA), according to the manufacturer's protocol. For intracellular cytokine staining, cells in coculture were incubated with brefeldin A ( $3 \mu \mathrm{g} / \mathrm{ml}$, Sigma) during the last $18 \mathrm{~h}$ of coculture, replicates $(\mathrm{n}=10)$ were pooled and T cells were labeled extracellularly using anti-CD3-AMCyan, anti-CD4PECy7 and anti-CD25-FITC (all BD Biosciences) antibodies. Next, cells were fixed and intracellularly labeled using Intrastain reagents (DakoCytomation, Heverlee, Belgium) with PE-labeled antibodies directed against IL-17 (Ebioscience, San Diego, Calif., USA), Alexa 700-conjugated antibodies against IFN- $\gamma$ (BD Biosciences) and allophycocyanin (APC)-labeled antibodies against IL-10 (Miltenyi Biotec) before acquisition on aN LSRII flow cytometer (BD Biosciences) and analyzed using FlowJo software version 8.7.3 (Tree Star Inc., Ashland, Oreg., USA). The core population of live CD3+ T cells was analyzed for IL-17 production while activated and $\mathrm{CD}^{\mathrm{dim}} \mathrm{T}$ cells were also included in IFN- $\gamma$ production analysis.

\section{Statistical Analysis}

Friedman followed by Dunn's multiple-comparisons post-hoc test or, where indicated, Wilcoxon's test was used to determine the differences between the results for hLF1-11-differentiated and control (peptide-incubated) DCs. Data are expressed as median and range. Two-sided $\mathrm{p}$ values are reported and the level of significance was set at $\mathrm{p}<0.05$.

\section{Results}

\section{Morphology and Cell Surface Molecule Expression} by hLF1-11-Differentiated and Control

(Peptide-Incubated) iDCs and Mature DCs

First, we inspected the morphology of the DCs that had been differentiated in the presence of hLF1-11 or the control peptide. The morphology, density and attachment of the cells to the wells did not differ between hLF111 and control (peptide-incubated) DCs. Next, we compared cell surface molecule expression by hLF1-11-differentiated and control (peptide-incubated) iDCs as an easy read-out for possible hLF1-11-induced phenotypic differences by these DCs. The results revealed that 
Table 1. Cell surface molecule expression by hLF1-11 and control (peptide-differentiated) DCs

\begin{tabular}{|c|c|c|c|c|c|c|c|}
\hline & & \multicolumn{3}{|l|}{ Immature DCs } & \multicolumn{3}{|c|}{ C. albicans-matured DCs } \\
\hline CD14 & LPS coreceptor & $2(1-3)$ & $4(2-7)^{*}$ & $2(1-3)$ & $3(2-7)$ & $2(1-6)$ & $2(0-6)$ \\
\hline CD197 & CCR7 & $8(5-17)$ & $12(7-19)$ & $10(7-16)$ & $29(26-34)$ & $27(21-42)$ & $32(24-38)$ \\
\hline CD54 & ICAM-1 & $199(123-241)$ & $138(92-245)$ & $183(109-256)$ & $881(512-1,190)$ & $1,025(500-1,434)$ & $850(356-1,155)$ \\
\hline CD40 & Costimulatory & $52(30-81)$ & $57(31-89)$ & $56(20-68)$ & $86(52-127)$ & $77(42-127)$ & $70(26-104)$ \\
\hline CD86 & B7.2 & $14(0-26)$ & $7(2-48)$ & $11(4-25)$ & $407(233-459)$ & $247(217-375)^{*}$ & $382(317-466)$ \\
\hline HLA-DR & MHC class II & $46(24-100)$ & $63(36-252)^{*}$ & $45(21-73)$ & $170(97-399)$ & $138(86-517)$ & $147(68-365)$ \\
\hline CD11b & CRIII & $294(131-382)$ & $261(104-299)$ & $288(201-379)$ & $278(183-320)$ & $224(189-304)$ & $269(226-396)$ \\
\hline CD206 & Mannose receptor & $45(32-71)$ & $33(22-152)$ & $54(27-75)$ & $30(17-45)$ & $31(16-44)$ & $33(19-53)$ \\
\hline CD209 & DC-SIGN & $44(29-66)$ & $44(19-74)$ & $42(23-54)$ & $41(23-49)$ & $41(26-51)$ & $33(23-50)$ \\
\hline Dectin-1 & $\beta$-Glucan receptor & $13(9-23)$ & $19(13-39)^{*}$ & $12(7-19)$ & $20(10-25)$ & $19(11-28)$ & $21(14-34)$ \\
\hline
\end{tabular}

Results are expressed as MFI from which background fluorescence by unlabeled cells was subtracted from the values for labeled cells. Data are expressed as medians and ranges (in parentheses) in experiments with at least 6 different donors. ${ }^{*} \mathrm{p}<0.05$.

hLF1-11-differentiated iDCs expressed significantly higher levels of HLA class II and dectin-1, a receptor involved in C. albicans recognition, on their cell-surface as compared to control (peptide-incubated) iDCs on their surface. In addition, expression of CD14 and CD80 was marginally enhanced (table 1). Upon maturation by $C$. albicans, the expression of the maturation marker CD83 as well as the costimulatory molecule CD 86 by hLF1-11differentiated DCs was significantly decreased as compared to control (peptide-incubated) DCs (table 1).

\section{Endocytic and Phagocytic Properties of}

hLF1-11-Differentiated and Control

(Peptide-Incubated) DCs

Since hLF1-11-differentiated DCs seemed to be affected by hLF1-11 treatment during differentiation, we compared the endocytic and phagocytic capacities of iDCs differentiated in the presence of hLF1-11 with those of control (peptide-incubated) iDCs. No significant difference in dextran uptake between hLF1-11-differentiated iDCs and control (peptide-incubated) iDCs was observed (fig. 1a). In addition, phagocytosis of $S$. aureus by hLF1-11-differentiated iDCs did not differ from that by control (peptide-incubated) iDCs (fig. 1b). However, the percentage of C. albicansphagocytosing hLF1-11-differentiated iDCs was significantly higher than that of control (peptide-incubated) iDCs (fig. 1c). Control experiments at $4^{\circ} \mathrm{C}$ revealed that approximately $10 \%$ of the iDCs bound C. albicans at all intervals of time, independent of the presence of hLF1-11 or control peptide during differentiation (data not shown).

\section{ROS Production by hLF1-11-Differentiated and}

Control (Peptide-Incubated) iDCs in Response to C. albicans

Since hLF1-11-differentiated iDCs displayed enhanced phagocytosis of C. albicans, we next determined the production of ROS by the various iDCs in response to this yeast. Results revealed that hLF1-11-differentiated iDCs produced significantly more ROS 30 and $60 \mathrm{~min}$ after stimulation with $C$. albicans than control (peptideincubated) iDCs (fig. 2).

\section{Differential Cytokine Production Patterns in \\ hLF1-11-Differentiated DCs and Control \\ (Peptide-Incubated) DCs}

Another functional property of DCs is the production of inflammatory mediators. We therefore assessed the pro- and anti-inflammatory cytokine production by the various DCs in response to $C$. albicans. The results showed that heat-killed C. albicans-matured hLF1-11differentiated DCs produced significantly more IL- 6 and IL-10 and less IL-12p40 than control (peptide-incubated) DCs (fig. 3). The production of TNF- $\alpha$ did not differ between the various groups of DCs (fig. 3).

\section{Polarization of CD4+ T Cells by hLF1-11-}

Differentiated or Control (Peptide-Incubated) DCs

Next, we compared the ability of hLF1-11-differentiated DCs to direct $\mathrm{T}$ cell polarization and that of control (peptide-incubated) DCs using a Th17 favoring mix. The supernatants of the cocultures of hLF1-11-differentiated 


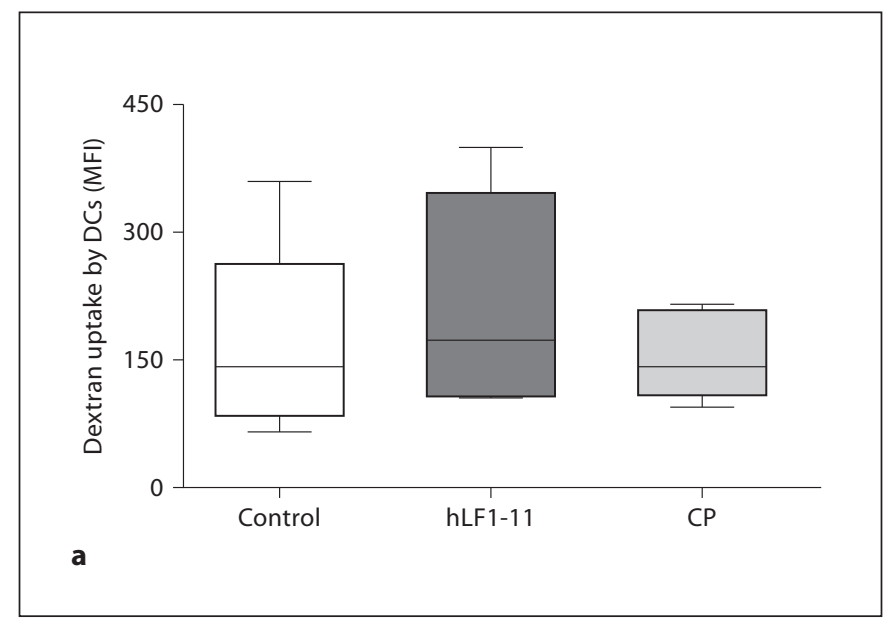

Fig. 1. Endocytosis of FITC-dextran and uptake of C. albicans and $S$. aureus by hLF1-11-differentiated and control (peptide-incubated) iDCs. Monocytes were cultured with rhGM-CSF and IL-4 in the presence of hLF1-11 (100 $\mu \mathrm{g} / \mathrm{ml}$, dark gray bars), control peptide (CP; $100 \mu \mathrm{g} / \mathrm{ml}$, light gray bars) or no peptide (open bars). At day 7, iDCs were harvested, washed and cultured for $2 \mathrm{~h}$ in the presence of FITC-dextran; thereafter the amount of dextran uptake by these cells was assessed by flow cytometry (a). Furthermore, after 60,90 or 120 min coincubation of the iDCs with pHrodo-labeled S. aureus, the percentage of pHrodo-positive iDCs was determined by flow cytometry (b). Lastly, iDCs were coincubated with CFSE-labeled C. albicans and after 15, 30 and 60 min coincubation, the percentage of iDCs associated with C. albicans was determined by flow cytometry (c). Boxes represent medians and second and third interquartiles, whiskers represent ranges in experiments with 6-10 different donors. ${ }^{*} \mathrm{p}<0.05$.
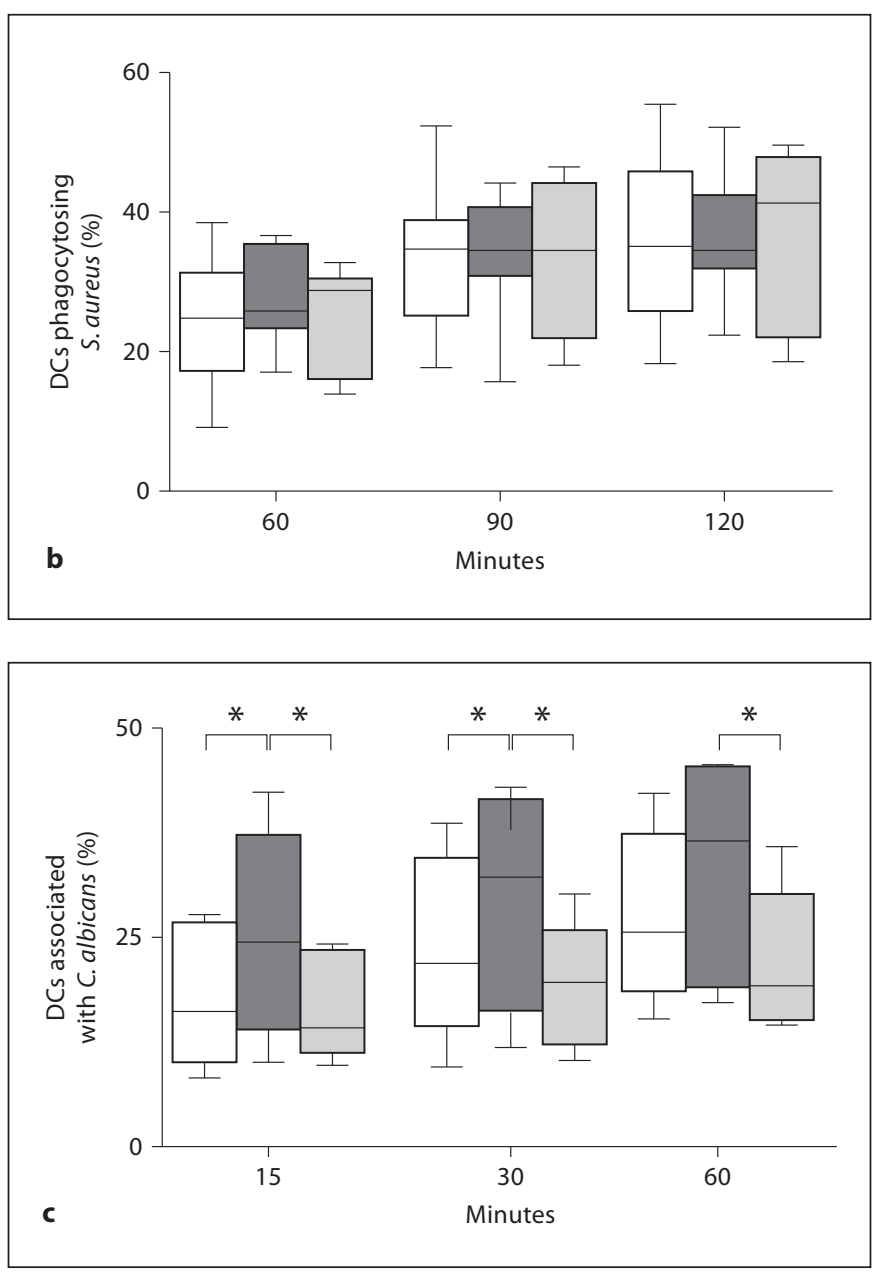

Fig. 2. Intracellular ROS production by hLF1-11-differentiated and control (peptide-incubated) iDCs. Monocytes were cultured with rhGM-CSF and IL-4 in the presence of hLF1-11 (100 $\mu \mathrm{g} / \mathrm{ml}$, dark gray bars), control peptide $(100 \mu \mathrm{g} / \mathrm{ml}$, light gray bars) or no peptide (open bars) and labeled DCFH-DA at day 7 with. Next, the labeled iDCs were stimulated with heatkilled C. albicans and the MFI was assessed directly and after 30,60 and 90 min as a measure of ROS production. Boxes represent medians and second and third interquartiles, whiskers represent ranges in experiments with 8 different donors. ${ }^{*} \mathrm{p}<0.05 ;{ }^{* *} \mathrm{p}<0.01$.

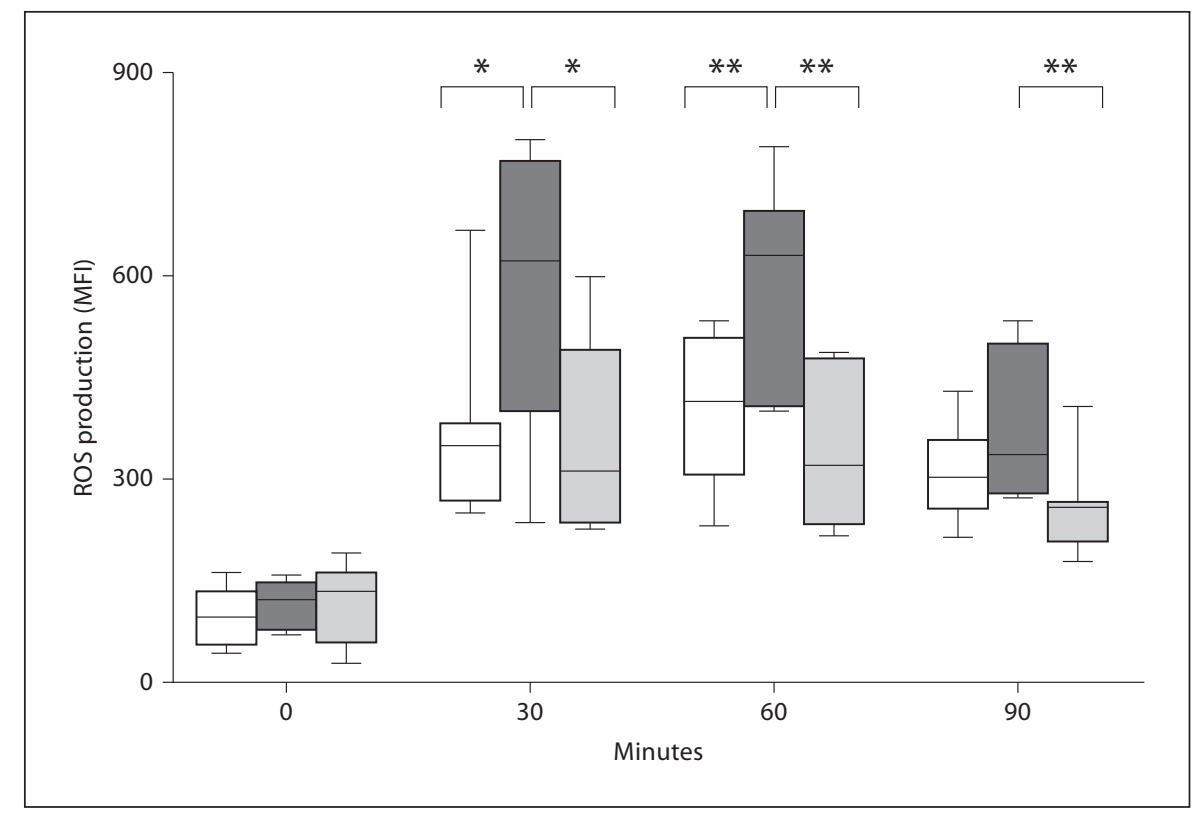




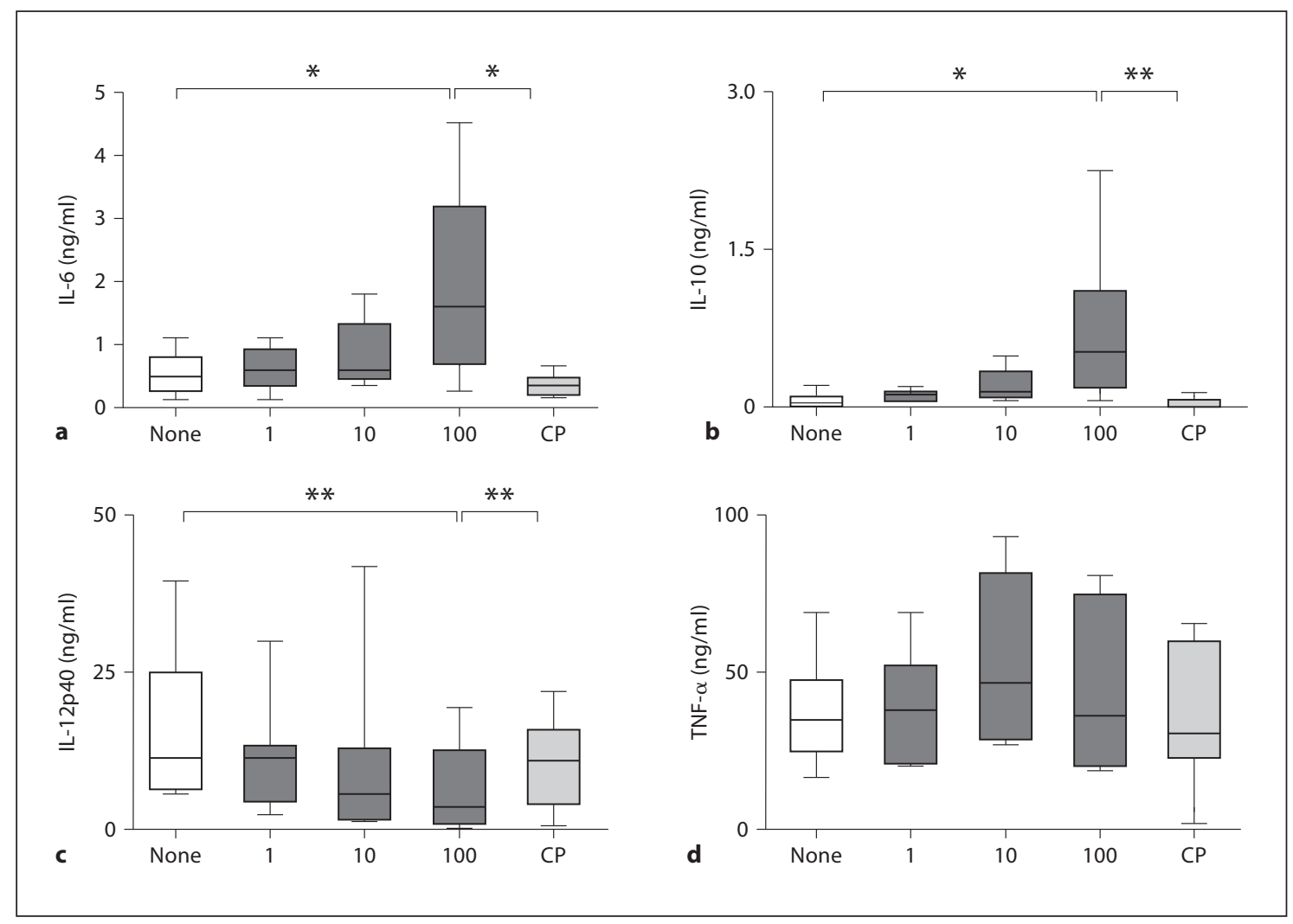

Fig. 3. Cytokine profiles of hLF1-11-differentiated and control (peptide-incubated) DCs in response to heat-killed C. albicans. Monocytes were cultured with rhGM-CSF and IL-4 in the presence of hLF1-11 (1, 10, $100 \mu \mathrm{g} / \mathrm{ml}$; dark gray bars) or control peptide (CP, $100 \mu \mathrm{g} / \mathrm{ml}$; light gray bars) for 6 days. Thereafter, cells were stimulated with $1 \times 10^{7}$ heat-killed C. albicans for $20 \mathrm{~h}$ and then supernatants were collected and assessed for IL-6 (a), IL-10

DCs with autologous CD4+ T cells contained significantly more IL-17 ( $\mathrm{p}<0.05)$ and IL-10 ( $\mathrm{p}=0.06)$, but less IFN$\gamma$ (fig. 4a) than the supernatants of cocultures with control (peptide-incubated) DCs. In these cultures, IL-2 was out of range and no IL- 4 was detected (data not shown). In addition, we determined the percentage of T-cells expressing the various cytokines (IL-17, IL-10 and IFN- $\gamma$ ) by intracellular cytokine staining. Results revealed that enhanced percentages of IL-17-producing T cells and reduced percentages of IFN- $\gamma$-producing $\mathrm{T}$ cells were found in the cocultures with hLF1-11-differentiated DCs as compared to control (peptide-incubated) DCs (fig. 4b). IL-10-producing T cells were present at very low frequencies and no differences in percentages of IL-10-producing $\mathrm{T}$ cells were found between the different groups (fig. $4 \mathrm{~b}$ ), suggesting that IL-10 in the supernatants of the coculture (fig. 4a) is mainly derived from the DCs.

hLF1-11 Promotes Antifungal Responses by Dendritic Cells (b), IL-12p40 (c) and TNF- $\alpha$ (d) levels. Values are expressed as fold increase of cytokine production compared to control DCs (none, no peptide; open bars). Data are expressed as boxes and whiskers; boxes represent medians and second and third interquartiles, whiskers represent ranges in experiments with 7 or 8 different donors. ${ }^{*} \mathrm{p}<0.05 ;{ }^{* *} \mathrm{p}<0.01$ as compared to control and control peptide-incubated DCs.

\section{Discussion}

In this study, we demonstrated that the presence of hLF1-11 during differentiation of monocytes into DCs results in DCs that promote antifungal responses to C. albicans and Th17 polarization. This conclusion is based on the following findings. First, phagocytosis of C. albicans and ROS production in response to this yeast were elevated in hLF1-11-differentiated DCs as compared to the control (peptide-incubated) DCs. Surprisingly, phagocytosis of $S$. aureus by hLF1-11-differentiated DCs was not enhanced. Second, the production of IL- 6 and IL10 by hLF1-11-differentiated DCs in response to C. albicans was significantly enhanced, while IL-12p40 production was reduced and TNF- $\alpha$ expression unaffected as compared to control (peptide-incubated) DCs. Incubation of hLF1-11-differentiated DCs with bacterial stimuli like 


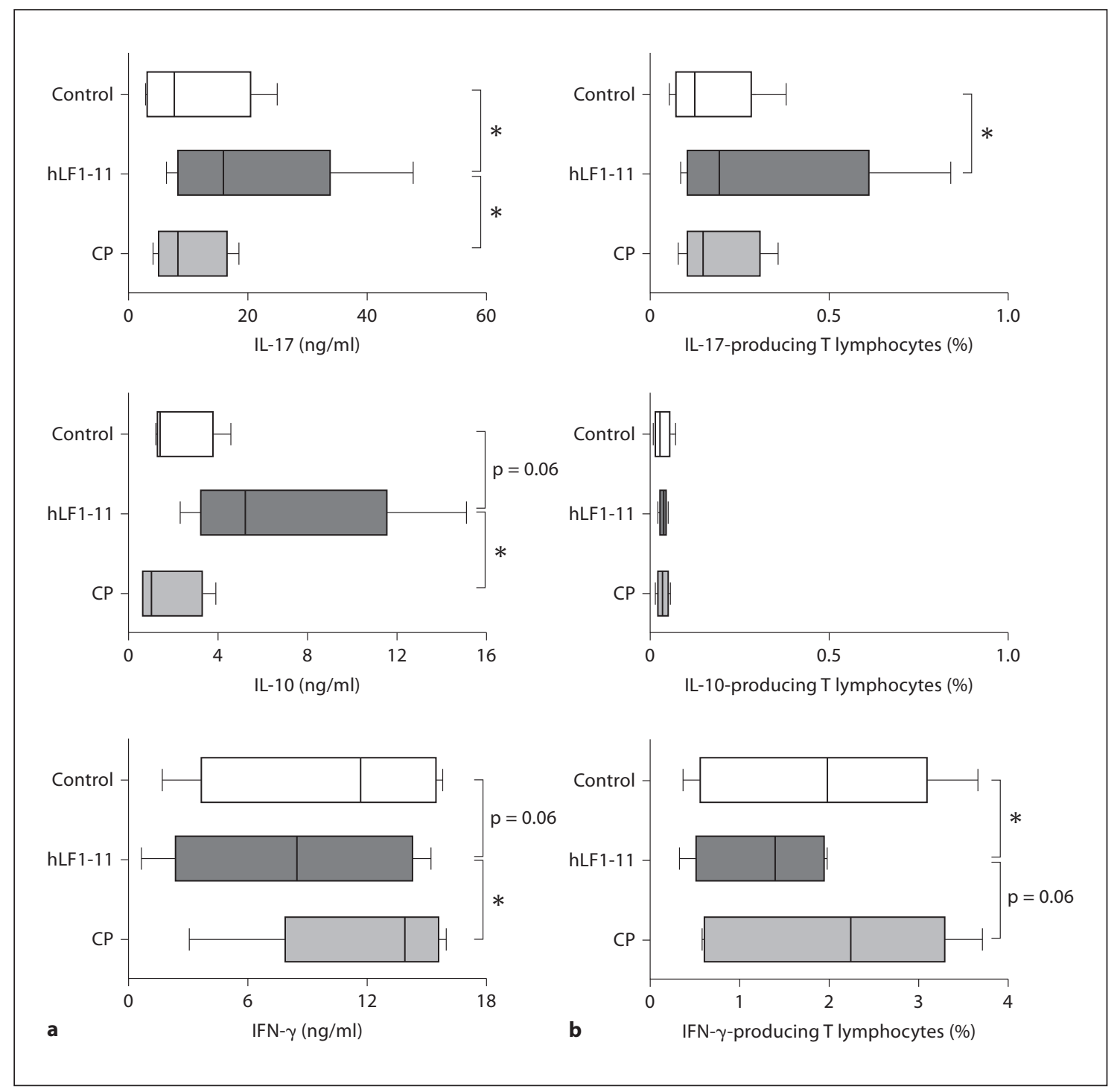

Fig. 4. Cytokine profile by CD4+ T cells after coculture with hLF1-11-differentiated and control (peptide-incubated) DCs. Monocytes were cultured with rhGM-CSF and IL-4 in the presence of hLF1-11 (100 $\mu \mathrm{g} / \mathrm{ml}$; dark gray bars), control peptide (CP, $100 \mu \mathrm{g} / \mathrm{ml}$; light gray bars), or saline (open bars) for 6 days. Thereafter, cells were stimulated with heat-killed $C$. albicans $(5 \times$ $105 / \mathrm{ml}$ ), purified protein derivative of $M$. tuberculosis (PPD; $5 \mu \mathrm{g} /$ $\mathrm{ml})$, TT; $150 \mathrm{lf} / \mathrm{ml})$ and LPS (100 ng/ml) for $24 \mathrm{~h}$. Next, cells were washed and CD4+ T cells from the same donor and TT were add- ed to the culture. Seventy-two hours later, supernatants were harvested and assessed for IL-17, IL-10 and IFN- $\gamma$ (a) and IL-4, IL-2 levels (data not shown). Next, intracellular cytokine production by the T-lymphocytes in the coculture was assessed by addition of brefeldin A for the last $16 \mathrm{~h}$ of the coculture $(3 \mu \mathrm{g} / \mathrm{ml})$. T cells were stained for intracellular IL-17, IL-10 and IFN- $\gamma(\mathbf{b})$. Data are expressed as boxes and whiskers; boxes represent medians and second and third interquartiles, whiskers represent ranges in experiments with 6-8 different donors. ${ }^{*} \mathrm{p}<0.05$.
LPS or lipoteichoic acid resulted in a significant $(\mathrm{p}<$ 0.05 ) reduction of TNF- $\alpha$ and IL-12p40 (without affecting the IL- 6 and IL-10 levels) as compared to control (peptide-incubated) DCs (online supplementary figure 1 and 2, www.karger.com/doi/10.1159/000332941). Together, these data indicate that the presence of hLF1-11 during mono-
cyte-DC differentiation has differential effects on the cytokine profile of the resulting DC upon maturation by fungal or bacterial stimulation. Interestingly, we reported earlier that the presence of hLF1-11 during GM-CSF-driven differentiation of monocytes into macrophages led to macrophages displaying enhanced production of IL-10, but not 
IL-12p40 or TNF- $\alpha$, in response to C. albicans [6]. In addition, these macrophages displayed enhanced antimicrobial properties against C. albicans as well as S. aureus. One possible explanation for the differential effects of hLF1-11 on monocyte-DC differentiation and monocyte-macrophage could involve myeloperoxidase - the major intracellular target of hLF1-11 [van der Does et al., submitted]. GM-CSF enhances the expression of myeloperoxidase in monocytes, thereby creating more 'target' for hLF1-11 for modulation, whereas GM-CSF and IL-4 (or IL- 4 alone) diminish myeloperoxidase expression [23].

The most striking finding of this study is that hLF1-11 drives differentiation of monocytes toward DCs that enhance Th17 polarization. Th17 responses are thought to be important in host defense against fungi and $S$. aureus [24-27], especially in the skin and mucosa. In addition, IL-17 is involved in the influx of neutrophils and can induce production of cytokines/chemokines and antimicrobial peptides by epithelial cells [28].

Although Th17 cells are part of the adaptive immune response, they serve mainly to regulate innate immune responses [29]. Currently, the mechanism(s) underlying the enhanced Th17 polarization by hLF1-11-differentiated DCs are not clear. However, Bouguermouh et al. [30] have shown that mature DCs are less capable of inducing Th17 polarization than iDCs due to reduced stimulation of CD28 on the T cells by CD80 and/or CD86. hLF1-11-differentiated DCs displayed reduced maturation as indicated by reduced CD83 expression as well as CD86 expression.

In addition to enhancing Th17 polarization, hLF1-11differentiated DCs reduced the IFN- $\gamma$ production by $\mathrm{CD} 4+\mathrm{T}$ cells. It cannot be excluded that this reduction of Th1 polarization is the consequence of the enhanced IL10 production by the hLF1-11-differentiated DCs in the cocultures [31].

Interestingly, the effects of hLF1-11 on monocyte-DC differentiation differ from those reported for other AMPs/HDPs, such as the human cathelicidin LL-37 and $\alpha$ - and $\beta$-defensins. Davidson et al. [14] showed that the presence of LL-37 during monocyte-DC differentiation resulted in DCs promoting IFN- $\gamma$-producing $\mathrm{T}$ cells. Kandler et al. [16] have shown that this peptide inhibited the response of iDCs toward microbial stimuli such as LPS, thereby indicating that LL-37 reduced the maturation of these cells. Others reported that human defensins HNP- 1 and hBD-1 promoted the activation and maturation of DCs and stimulated the production of TNF- $\alpha$, IL6 , and IL-12p70 but not IL-10 [32]. Together, hLF1-11 and LL-37/defensins differentially affect the differentiation and subsequent maturation of DCs and their ability to promote Th cell polarization.

The concentration of hLF1-11 in the present study $(100 \mu \mathrm{g} / \mathrm{ml})$ was determined based on dose-response experiments with monocytes, in earlier experiments $[6,18]$. In addition, hLF1-11 has been shown to be effective in mice up to concentrations of $4 \mathrm{mg} / \mathrm{kg}$ body weight, which corresponds to injection of $100 \mu \mathrm{g} /$ mouse. However, it should be realized that extrapolation of in vitro to in vivo levels is hampered as the local concentration of the peptide at the site of infection remains unknown.

Together, these data show that hLF1-11 is able to modulate monocyte-DC differentiation, resulting in DCs displaying enhanced antifungal responses against C. albicans and the ability to promote Th17 polarization after coculture with CD4+ T cells. The immunomodulatory properties of hLF1-11 may aid in balancing the immune responses of the host, leading to the resolution of infections by (multidrug)-resistant pathogens.

\section{Acknowledgements}

This work was financially supported by SenterNovem grant ISO44096, The Netherlands Organization for Scientific Research (VENI grant 916.86.115), the Gisela Thier Foundation of the Leiden University Medical Center and University of Leiden.

\section{References}

1 Zasloff M: Antimicrobial peptides of multicellular organisms. Nature 2002;415:389395.

$\checkmark 2$ Brogden KA: Antimicrobial peptides: pore formers or metabolic inhibitors in bacteria? Nat Rev Microbiol 2005;3:238-250.

$>3$ Nibbering PH, Ravensbergen E, Welling MM, van Berkel LA, van Berkel PH, Pauwels EK, Nuijens JH: Human lactoferrin and peptides derived from its $\mathrm{N}$ terminus are highly effective against infections with antibiotic- resistant bacteria. Infect Immun 2001;69: 1469-1476.

4 Konopka K, Dorocka-Bobkowska B, Gebremedhin S, Duzgunes N: Susceptibility of Candida biofilms to histatin 5 and fluconazole. Antonie Van Leeuwenhoek 2010;97: 413-417.

5 Lupetti A, Brouwer CP, Bogaards SJ, Welling MM, de Heer E, Campa M, van Dissel JT, Friesen RH, Nibbering PH: Human lactoferrin-derived peptide's antifungal activities against disseminated Candida albicans infection. J Infect Dis 2007;196:1416-1424.

6 6 van der Does AM, Bogaards SJ, Ravensbergen $\mathrm{B}$, Beekhuizen $\mathrm{H}$, van Dissel JT, Nibbering PH: Antimicrobial peptide hLF111 directs granulocyte-macrophage colonystimulating factor-driven monocyte differentiation toward macrophages with enhanced recognition and clearance of pathogens. Antimicrob Agents Chemother 2010;54:811816. 
7 Bowdish DM, Davidson DJ, Scott MG, Hancock RE: Immunomodulatory activities of small host defense peptides. Antimicrob Agents Chemother 2005;49:1727-1732.

8 Jenssen H, Hancock RE: Therapeutic potential of HDPS as immunomodulatory agents. Methods Mol Biol 2010;618:329-347.

-9 Hale JD, Hancock RE: Alternative mechanisms of action of cationic antimicrobial peptides on bacteria. Expert Rev Anti Infect Ther 2007;5:951-959.

10 Hancock RE, Sahl HG: Antimicrobial and host-defense peptides as new anti-infective therapeutic strategies. Nat Biotechnol 2006; 24:1551-1557.

- 11 Scott MG, Dullaghan E, Mookherjee N, Glavas $\mathrm{N}$, Waldbrook M, Thompson A, Wang A, Lee K, Doria S, Hamill P, Yu JJ, Li Y, Donini O, Guarna MM, Finlay BB, North JR, Hancock RE: An anti-infective peptide that selectively modulates the innate immune response. Nat Biotechnol 2007;25:465-472.

12 Nijnik A, Madera L, Ma S, Waldbrook M, Elliott MR, Easton DM, Mayer ML, Mullaly SC, Kindrachuk J, Jenssen H, Hancock RE: Synthetic cationic peptide IDR-1002 provides protection against bacterial infections through chemokine induction and enhanced leukocyte recruitment. J Immunol 2010;184: 2539-2550.

13 van der Does AM, Beekhuizen H, Ravensbergen B, Vos T, Ottenhoff TH, van Dissel JT, Drijfhout JW, Hiemstra PS, Nibbering PH: LL-37 directs macrophage differentiation toward macrophages with a proinflammatory signature. J Immunol 2010;185:1442-1449.

- 14 Davidson DJ, Currie AJ, Reid GS, Bowdish DM, MacDonald KL, Ma RC, Hancock RE, Speert DP: The cationic antimicrobial peptide LL-37 modulates dendritic cell differentiation and dendritic cell-induced $\mathrm{T}$ cell polarization. J Immunol 2004;172:1146-1156.

-15 Mookherjee N, Lippert DN, Hamill P, Falsafi R, Nijnik A, Kindrachuk J, Pistolic J, Gardy J, Miri P, Naseer M, Foster LJ, Hancock RE: Intracellular receptor for human host defense peptide LL-37 in monocytes. J Immunol 2009;183:2688-2696.
16 Kandler K, Shaykhiev R, Kleemann P, Klescz F, Lohoff M, Vogelmeier C, Bals R: The antimicrobial peptide LL-37 inhibits the activation of dendritic cells by TLR ligands. Int Immunol 2006;18:1729-1736.

17 Dijkshoorn L, Brouwer CP, Bogaards SJ, Nemec A, van den Broek PJ, Nibbering PH: The synthetic N-terminal peptide of human lactoferrin, $\mathrm{hLF}(1-11)$, is highly effective against experimental infection caused by multidrug-resistant Acinetobacter baumannii. Antimicrob Agents Chemother 2004;48: 4919-4921.

18 van der Does AM, Bogaards SJ, Jonk L, Wulferink M, Velders MP, Nibbering PH: The human lactoferrin-derived peptide hLF1-11 primes monocytes for an enhanced TLR-mediated immune response. Biometals 2010;23: 493-505.

19 Zenaro E, Donini M, Dusi S. Induction of Th1/Th17 immune response by Mycobacterium tuberculosis: role of dectin-1, mannose receptor, and DC-SIGN. J Leukoc Biol 2009; 86:1393-1401.

20 Bettelli E, Korn T, Oukka M, Kuchroo VK: Induction and effector functions of $\mathrm{T}_{\mathrm{H}} 17$ cells. Nature 2008;453:1051-1057.

21 Brenchley JM, Paiardini M, Knox KS, Asher AI, Cervasi B, Asher TE, Scheinberg P, Price DA, Hage CA, Kholi LM, Khoruts A, Frank I, Else J, Schacker T, Silvestri G, Douek DC: Differential Th17 CD4 t-cell depletion in pathogenic and nonpathogenic lentiviral infections. Blood 2008;112:2826-2835.

22 Louten J, Boniface K, de Waal Malefyt R: Development and function of Th17 cells in health and disease. J Allergy Clin Immunol 2009;123:1004-1011.

23 Roy KC, Bandyopadhyay G, Rakshit S, Ray M, Bandyopadhyay S: IL-4 alone without the involvement of GM-CSF transforms human peripheral blood monocytes to a CD1a ${ }^{\mathrm{dim}}$, $\mathrm{CD} 3^{+}$myeloid dendritic cell subset. J Cell Sci 2004; 117:3435-3445.
24 Conti HR, Gaffen SL: Host responses to Candida albicans: Th17 cells and mucosal candidiasis. Microbes Infect 2010;12:518-527.

25 Eyerich K, Foerster S, Rombold S, Seidl HP, Behrendt H, Hofmann H, Ring J, TraidlHoffmann C: Patients with chronic mucocutaneous candidiasis exhibit reduced production of Th17-associated cytokines IL-17 and IL-22. J Invest Dermatol 2008;128:26402645.

26 Iwakura Y, Nakae S, Saijo S, Ishigame H: The roles of IL-17 $\alpha$ in inflammatory immune responses and host defense against pathogens. Immunol Rev 2008;226:57-79.

27 Cho JS, Pietras EM, Garcia NC, Ramos RI, Farzam DM, Monroe HR, Magorien JE, Blauvelt A, Kolls JK, Cheung AL, Cheng G, Modlin RL, Miller LS: IL-17 is essential for host defense against cutaneous Staphylococcus aureus infection in mice. J Clin Invest 2010;120:1762-1773.

28 Onishi RM, Gaffen SL: Interleukin-17 and its target genes: mechanisms of interleukin-17 function in disease. Immunology 2010;129: 311-321.

29 Yu JJ, Gaffen SL: Interleukin-17: a novel inflammatory cytokine that bridges innate and adaptive immunity. Front Biosci 2008; 13:170-177.

30 Bouguermouh S, Fortin G, Baba N, Rubio M, Sarfati M: CD28 co-stimulation down regulates Th17 development. PLoS One 2009; 4:e5087.

31 Hamad M: Antifungal immunotherapy and immunomodulation: a double-hitter approach to deal with invasive fungal infections. Scand J Immunol 2008;67:533543.

32 Presicce P, Giannelli S, Taddeo A, Villa ML, Della Bella S: Human defensins activate monocyte-derived dendritic cells, promote the production of proinflammatory cytokines, and up-regulate the surface expression of CD91. J Leukoc Biol 2009;86:941948. 